\title{
A Geochemical and Textural Cross- Section of a Compositionally Zoned Magma Reservoir
}

\author{
JOHN M. ZAYAC ${ }^{1,2, *}$, MARC-ANTOINE LONGPRÉ2,1 \\ ${ }^{1}$ Earth and Environmental Sciences, The Graduate Center, \\ City University of New York, USA \\ (*jzayac@gradcenter.cuny.edu) \\ ${ }^{2}$ School of Earth and Environmental Science, Queens \\ College, City University of New York, USA
}

Continuous, compositionally zoned eruptions provide a unique opportunity to probe the pre-eruptive distribution of volatiles, chemical species, and phases (melt, crystals, and bubbles) in magmatic systems as they are often interpreted to represent progressive withdrawal from a stratified reservoir. Here we present the results of a fine-scale cross-stratigraphic study of a dacite to andesite zoned eruption from Cosigüina volcano, Nicaragua. From samples collected at $10 \mathrm{~cm}$ spacing across the 170-cm-thick pumice-scoria fall deposit, we analyzed the composition of matrix glasses and plagioclasehosted melt inclusions for major, trace and volatile elements and performed vesicularity and crystallinity measurements. Matrix glasses show near homogeneous microlite-poor, dacitic $\left(67 \mathrm{wt} \% \mathrm{SiO}_{2}\right)$ and microlite-rich, andesitic (58 wt $\%$ $\mathrm{SiO}_{2}$ ) end-member compositions at either ends of the deposit stratigraphy, separated by a narrow transition zone spanning $\sim 12 \%$ of deposit. Melt inclusion $\mathrm{H}_{2} \mathrm{O}(\sim 2.5-4 \mathrm{wt} \%)$ and $\mathrm{CO}_{2}$ $(<100 \mathrm{ppm})$ contents exhibit little stratigraphic variation. Concentrations of F (400-800 ppm) and Cl (1000-2000 ppm) decrease by $\sim 50 \%$ from dacite to andesite, while S (200-800 ppm) contents abruptly increase. Interestingly, vesicularity shifts from $>90 \%$ in dacite to $\sim 45 \%$ in andesite and correlates more with stratigraphy than composition, which may reflect pre-eruptive exsolved volatile gradients in the magma reservoir. Total crystallinity also trends with stratigraphy from $<5 \%$ in early dacite to $\sim 50 \%$ in late andesite, accompanied by a shift in plagioclase phenocryst compositions from $\mathrm{An}_{40-65}$ to $\mathrm{An}_{75-90 . .}$ We interpret these results to suggest that this eruption originated from a continuous, compositionally zoned magma body, that the early erupted dacite was derived from the andesite, and that crystallization-driven volatile exsolution most likely triggered this eruption. 